NASA/TM-2002-211752

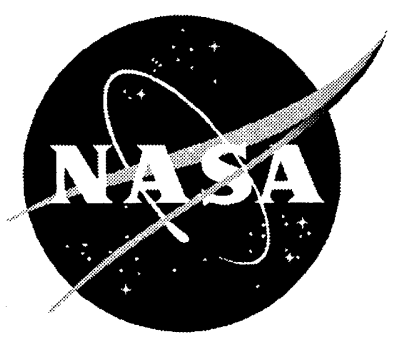

\title{
Airframe Research and Technology for Hypersonic Airbreathing Vehicles
}

David E. Glass, N. Ronald Merski, and Christopher E. Glass

Langley Research Center, Hampton, Virginia 


\section{The NASA STI Program Office ... in Profile}

Since its founding, NASA has been dedicated to the advancement of aeronautics and space science. The NASA Scientific and Technical Information (STI) Program Office plays a key part in helping NASA maintain this important role.

The NASA STI Program Office is operated by Langley Research Center, the lead center for NASA's scientific and technical information. The NASA STI Program Office provides access to the NASA STI Database, the largest collection of aeronautical and space science STI in the world. The Program Office is also NASA's institutional mechanism for disseminating the results of its research and development activities. These results are published by NASA in the NASA STI Report Series, which includes the following report types:

- TECHNICAL PUBLICATION. Reports of completed research or a major significant phase of research that present the results of NASA programs and include extensive data or theoretical analysis. Includes compilations of significant scientific and technical data and information deemed to be of continuing reference value. NASA counterpart of peer-reviewed formal professional papers, but having less stringent limitations on manuscript length and extent of graphic presentations.

- TECHNICAL MEMORANDUM. Scientific and technical findings that are preliminary or of specialized interest, e.g., quick release reports, working papers, and bibliographies that contain minimal annotation. Does not contain extensive analysis.

- CONTRACTOR REPORT. Scientific and technical findings by NASA-sponsored contractors and grantees.
- CONFERENCE PUBLICATION. Collected papers from scientific and technical conferences, symposia, seminars, or other meetings sponsored or co-sponsored by NASA.

- SPECIAL PUBLICATION. Scientific, technical, or historical information from NASA programs, projects, and missions, often concerned with subjects having substantial public interest.

TECHNICAL TRANSLATION. Englishlanguage translations of foreign scientific and technical material pertinent to NASA's mission.

Specialized services that complement the STI Program Office's diverse offerings include creating custom thesauri, building customized databases, organizing and publishing research results ... even providing videos.

For more information about the NASA STI Program Office, see the following:

- Access the NASA STI Program Home Page at http://www.sti.nasa.gov

- Email your question via the Internet to help@sti.nasa.gov

- Fax your question to the NASA STI Help Desk at (301) 621-0134

- Telephone the NASA STI Help Desk at (301) 621-0390

- Write to:

NASA STI Help Desk

NASA Center for AeroSpace Information 7121 Standard Drive Hanover, MD 21076-1320 
NASA/TM-2002-211752

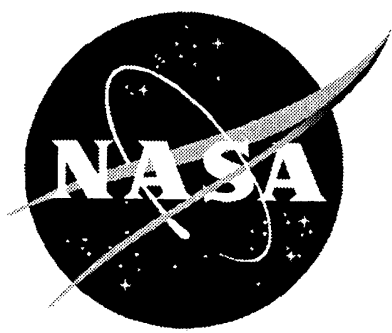

\section{Airframe Research and Technology for Hypersonic Airbreathing Vehicles}

David E. Glass, N. Ronald Merski, and Christopher E. Glass

Langley Research Center, Hampton, Virginia

National Aeronautics and

Space Administration

Langley Research Center

Hampton, Virginia 23681-2199

July 2002 
Available from:

NASA Center for AeroSpace Information (CASI)

7121 Standard Drive

Hanover, MD 21076-1320

(301) 621-0390
National Technical Information Service (NTIS) 5285 Port Royal Road

Springfield, VA 22161-2171

(703) 605-6000 


\title{
Airframe Research and Technology for Hypersonic Airbreathing Vehicles
}

\author{
David E. Glass*, N. Ronald Merski, and Christopher E. Glass \\ NASA Langley Research Center, Hampton, VA 23681
}

\begin{abstract}
The Hypersonics Investment Area (HIA) within NASA's Advanced Space Transportation Program (ASTP) has the responsibility to develop hypersonic airbreathing vehicles for access to space. The Airframe Research and Technology (AR\&T) Project, as one of six projects in the HIA, will push the state-of-the-art in airframe and vehicle systems for low-cost, reliable, and safe space transportation. The individual technologies within the project are focused on advanced, breakthrough technologies in airframe and vehicle systems and crosscutting activities that are the basis for improvements in these disciplines. Both low and medium technology readiness level (TRL) activities are being pursued. The key technical areas that will be addressed by the project include analysis and design tools, integrated vehicle health management (IVHM), composite (polymer, metal, and ceramic matrix) materials development, thermal/structural wall concepts, thermal protection systems, seals, leading edges, aerothermodynamics, and airframe/propulsion flowpath technology. Each of the technical areas or subprojects within the Airframe R\&T Project is described in this paper.
\end{abstract}

\section{INTRODUCTION}

NASA's Integrated Space Transportation Plan (ISTP) includes a) Space Shuttle Upgrades, b) the Space Launch Initiative ( $2^{\text {nd }}$ Gen), and C) the Advanced Space Transportation Program (ASTP). Part of the ASTP is the $3^{\text {rd }}$ Generation Access to Space, which NASA refocused beginning in $\mathrm{FYO2}$ to airbreathing propulsion vehicles, and called the effort the Hypersonics Investment Area (HIA). Within the HIA, are six projects: Airframe Research and Technology, Propulsion Research and Technology, Systems Analysis, Rocket Based Combined Cycles Propulsion, Revolutionary Turbine Accelerators, and Hypersonic Demonstrators. The focus herein is the Airframe Research and Technology project.

The goal of the Airframe project is to develop and demonstrate airframe technologies for hypersonic airbreathing vehicles providing significant increases in performance margin that result in reductions in cost of space transportation systems (\$100//b to LEO) while dramatically improving the safety and operability of those systems $(1 / 1,000,000$ chance of vehicle loss). There are three main objectives for the Airframe project:

- Increased weight margin

- Increased combined loads margin

- Thermal

- Structural

\author{
- Aerothermodynamics \\ - Increased operational margin
}

The technical challenges associated with achieving the Airframe project goals and objectives for airbreathing hypersonic vehicles include low drag, minimum weight, flight from Mach 0-25-0 (takeoff, flight to LEO, deorbit, and landing), tight aerodynamic control margins, high volumetric efficiency, and high dynamic pressure flight.

Technical challenge differences between rocket and airbreather airframe are sometimes less obvious than those for just the propulsion system, but they are no less important or significant. Examples of rocket versus airbreathing propulsion vehicles are shown in Fig. 1. The TPS for airbreathers may be driven by the long ascent time and the resulting high-integrated heat load, however, high descent heating rates must be investigated. Because low-drag, sharp leading edges are often a requirement, a much higher stagnation heat flux results than for the blunt leading edges often utilized on rocket propulsion vehicles. Also, the need for low drag leads one to consider conformal tanks for airbreathers versus cylindrical tanks for rockets. The structure is significantly different, with airbreathers often having highly loaded wings, hot control surfaces, and an airframe that is highly integrated with the propulsion system. In addition, landing gear on an airbreather is sized for a fully loaded (full fuel tank) takeoff versus a lightly loaded (empty tanks) landing for a rocket.
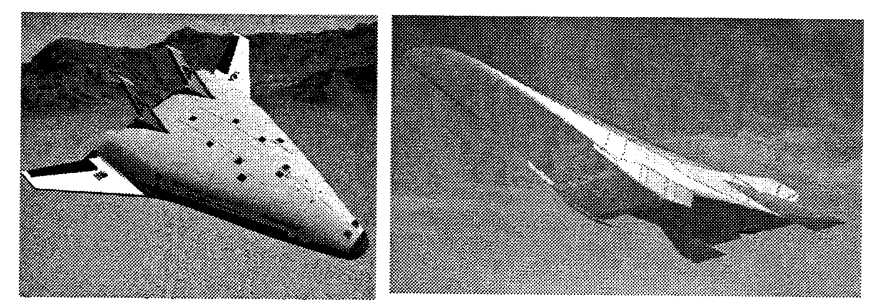

Fig. 1 Example of rocket versus airbreather single stage to orbit (SSTO) concepts.

The approach to address the airframe technical challenges is to focus on structures and materials, aerothermodynamics, and airframe/propulsion flowpath technology. The structures and materials technology development includes tasks in the areas of Integrated Airframe Design, Integrated Thermal Structures and Materials, and Thermal Protection Systems. The aerothermodynamics and flowpath technology development includes aerodynamics, aeroheating, and ground-based facility testing at NASA Langley and NASA Ames. A mix of medium and low TRL technologies are being addressed by the project. The approaches taken to address the

The use of trademarks or names of manufacturers in this paper is for accurate reporting and does not constitute an official endorsement, either expressed or implied, of such products or manufacturers by the National Aeronautics and Space Administration.

*E-mail: d.e.glass@larc.nasa.gov 
technical challenges and increase performance margin and reusability include:

- Conformal tanks

- Thin control surfaces

- Hot structures

- High Mach number staging

- Boundary layer transition

- Sharp leading edges

- Thin thermal protection systems

- High fidelity design and analysis tools

- Dynamic seals

- Airframe health monitoring

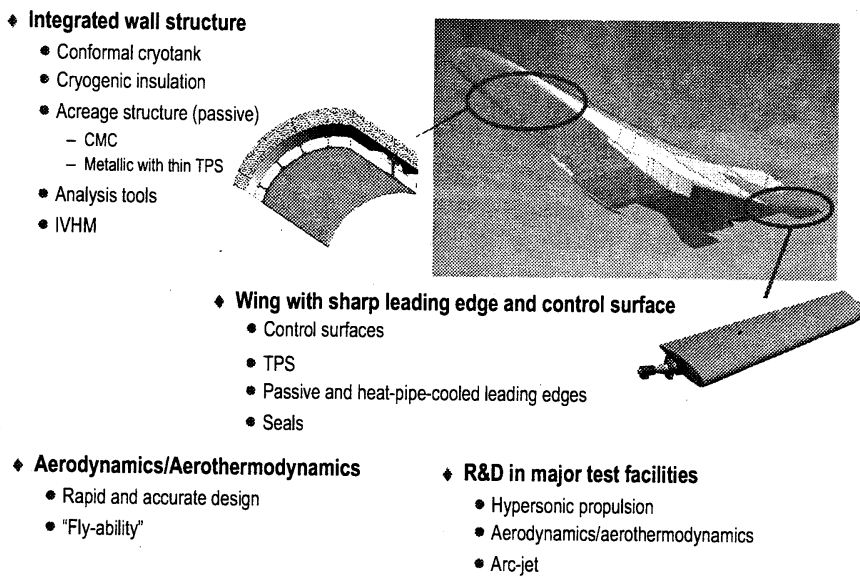

Fig. 2 Airframe technical focus.

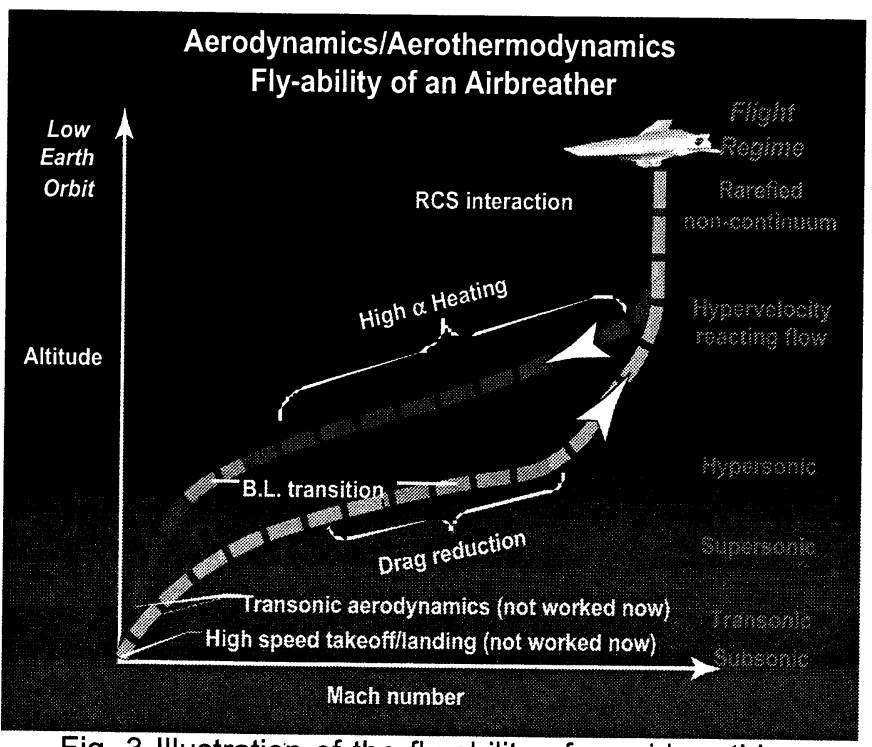

Fig. 3 Illustration of the fly-ability of an airbreathing vehicle.

The Airframe project technical focus is illustrated in Fig. 2. In the area of structures and materials, multiple aspects of an integrated wall structure and a wing with a sharp leading edge and control surface are being worked. In addition to structures and materials, the Airframe project includes work in aerothermodynamics, which focuses on flyability and survivability of a vehicle. Technical challenges in this area (shown in Fig. 3) include drag reduction, boundary layer transition, high angle of attack heating, and reaction control system (RCS) interactions.

\section{DESCRIPTION OF TASKS}

When originally instituted, the Airframe R\&T Project was a base funding activity for high risk SSTO tasks, however, the project underwent a major re-planning activity in FY01 for FY02. New tasks were identified and developed for each of five sub-projects: Integrated Airframe Design, Integrated Thermal Structures and Materials, Thermal Protection Systems, Aerothermodynamics, and Airframe/ Propulsion Flowpath Technology. Note that some of the FY02 tasks include continuation of work that was ongoing in FY01, while other tasks represent entirely new activities. Thus, the FY02 sub-projects and tasks are described in detail below. Also, a brief discussion of the Airframe/Propulsion Flowpath Technology sub-project is discussed.

\section{Integrated Airframe Design}

The objectives of the Integrated Airframe Design subproject include development of design and analysis tools to provide accurate and rapid airframe structure design and the integration of health monitoring into the airframe structure and TPS. The Analysis and Design Tools task has efforts focused on rapid design and analysis, design for uncertainty, and fail safe analysis and design tools. The Airframe Health Monitoring task is focused on multiparameter and high-temperature fiber-optic sensors.

There are three subtasks within the Analysis and Design Tools task. These subtasks are: Tools for Rapid Design and Analysis, Design Tools for Uncertainty, and Fail Safe Analysis and Design Tools.

The objectives of the Tools for Rapid Design and Analysis subtask are to develop methods and techniques leading to substantial reduction in time for design of airframe structures and structural components, replace traditional empirical knock-down factors for design, and develop hierarchical modeling of heat transfer in built-up structures for direct compatibility with structural finite element analysis. One approach is to develop and verify advanced analysis tools using hierarchical, high-fidelity analyses that accounts for details at all levels of the airframe structure, sensitivity analysis/multi-disciplinary optimization, geometrically nonlinear response, material nonlinearity, damage initiation and growth, damage-mode interaction, and coupled thermal and structural analyses. A second approach is to utilize an Advanced Engineering Environment with rapid modeling and analysis requiring reduced pre- and post-processing, ultra-rapid, high- and variable-fidelity analyses, and interactive and real-time analyses with 3D immersive capabilities.

Next, the objective of the Design Tools for Uncertainty subtask is to develop verified fail-safe structures design and analysis technologies that increase reliability and performance. The approach taken to achieve this goal 
includes: development of advanced stochastic finite element technology to speed calculation of reliability; development of sensitivity analysis capability for both probabilistic and possibilistic analysis; execution of trade studies that relate risk, cost, and performance; integration of high-fidelity analysis technology and advanced damage tolerance methodologies with reliability and optimization technology; and the development of validated codes for large-scale, reliability based damage-tolerant structural design.

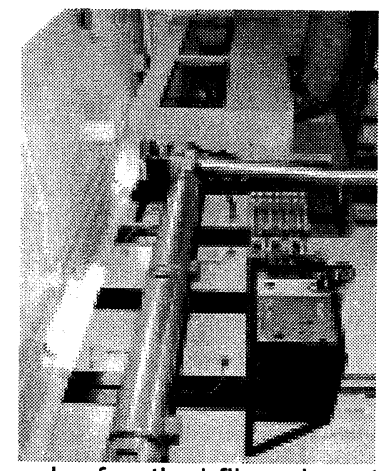

Fig. 4 Photograph of optical fiber draw tower at NASA Langley.

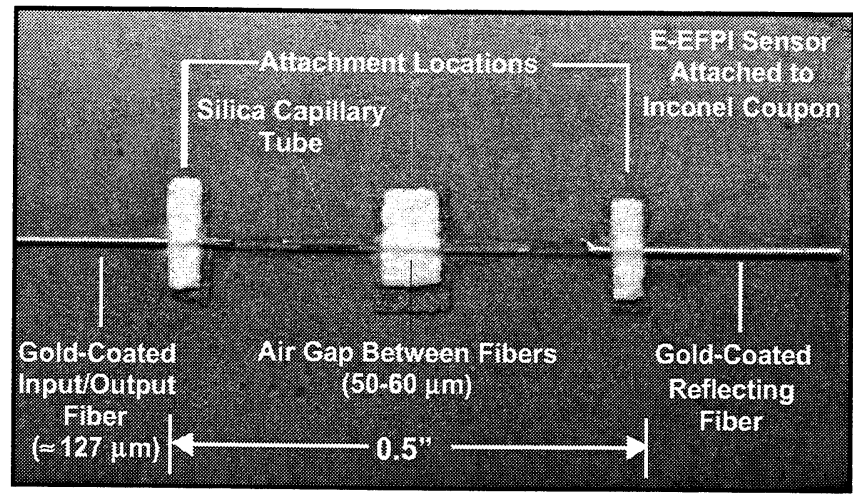

Fig. 5 Details of a high-temperature fiber optic strain sensor installed on an Inconel 601 specimen.

The objective of the final subtask, Fail Safe Analysis and Design Tools, is to develop and validate an efficient progressive damage prediction methodology to determine the residual strength and stiffness of composite structures that includes ply damage modes and allows for ply property degradation and geometrically nonlinear response. The approach taken is to develop nonlinear analysis methods and use them in conjunction with the currently existing damage progression methods and tools; develop damage propagation analyses with nonlinear material constitutive laws and failure criteria; develop damage propagation analyses for repeated loading conditions; develop structural design and sizing capabilities that will include nonlinear structural integrity analysis in the design process to assure adequate residual strength for all potential damage conditions; and use of selected experiments to verify the advanced design and analysis methodologies from the material coupon to the structural element and to the sub-component design levels

The goal of the Airframe Health Monitoring task is to develop multi-parameter and high-temperature optical fiber sensors. The target component for these sensors is both metallic and composite structure ${ }^{1-2}$. This task builds on the success of X-33 fiber-optic sensor development to develop multi-parameter demodulation techniques, and utilize high temperature coatings and fiber materials to develop high temperature sensors ${ }^{3}$. The multi-parameter sensors will provide single optical fiber strands that provide hundreds of measurements of structural parameters, such as strain, temperature, vibration, chemical environment, etc., that can be embedded or bonded to hypersonic vehicle structural elements for in-flight health monitoring ${ }^{4}$. The photograph presented in Fig. 4 shows the optical fiber draw tower at NASA Langley Research Center.

In addition, a program has been established with the goal of developing fiber optic strain sensors with a $3000^{\circ} \mathrm{F}$ temperature capability ${ }^{5}$. The details of a high-temperature fiber optic strain sensor installed on an Inconel 601 specimen is shown in Fig. 5. Also, a high-temperature fiber optic strain sensor installed on Inconel 601 and $\mathrm{C} / \mathrm{SiC}$ specimens is shown in Fig. 6.

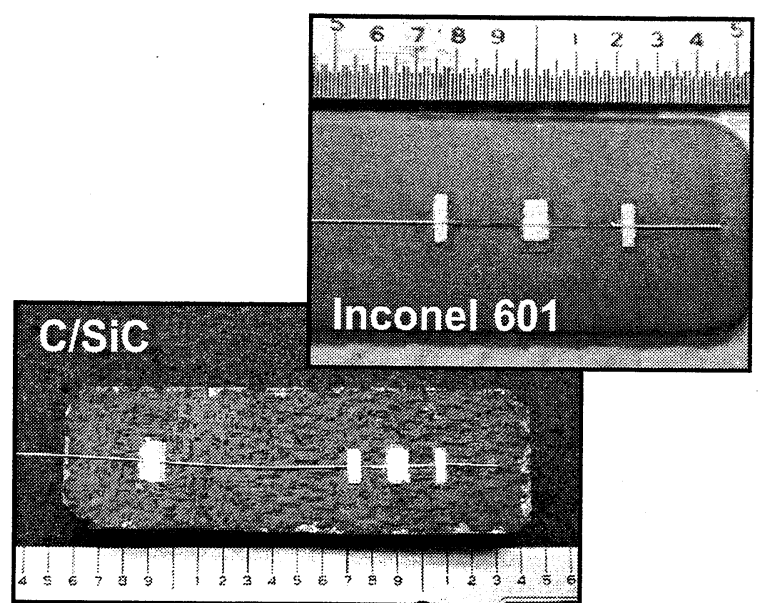

Fig. 6 High-temperature fiber optic strain sensor installed on Inconel 601 and $\mathrm{C} / \mathrm{SiC}$ specimens.

\section{Integrated Thermal Structures and Materials}

The next sub-project is the Integrated Thermal Structures and Materials, with objectives of: polymer matrix composite (PMC), metal matrix composite (MMC), and ceramic matrix composite (CMC) materials development, and development of wall structural concepts. Efficient and reliable hot wing structures with low maintenance and fabrication costs and efficient and reliable conformal cryotank structures with low maintenance and fabrication costs are part of the long-range goals of this sub-project. This sub-project consists of four tasks. The PMC Constituents and Processes task is focused on nonautoclave fabrication of large cryotanks and the 
development of PMC's with LOX and $\mathrm{LH}_{2}$ barrier properties and enhanced toughness for use as cryotank structure. Next, the MMC Constituents and Processes task is focused on advanced $\mathrm{Ti}$ and intermetallic MMC's for $1200^{\circ} \mathrm{F}-1500^{\circ} \mathrm{F}$ applications, novel lightweight metallic systems for $1500^{\circ} \mathrm{F}-2000^{\circ} \mathrm{F}$ applications, efficient joining processes, and lightweight protective coatings. The CMC Constituents and Processes task is focused on reproducible CMC materials with improved mechanical reliability and cyclic durability enabling for airframe structures. The final task, Integrated Airframe Structure Development, is focused on the development and validation of structural systems that show the best potential of meeting program goals for the vision vehicle.

The PMC Constituents and Processes task is focused on cryotanks and airframe primary structure, specifically, non-autoclave PMC materials and adhesives, hightemperature polyimides $\left(\sim 600^{\circ} \mathrm{F}\right)$, and LOX compatible polyimide cryo-insulation $\left(\sim 400-450^{\circ} \mathrm{F}\right)$. The objectives of the task include non-autoclave fabrication of large cryotanks and the development of PMC's with LOX and $\mathrm{LH}_{2}$ barrier properties and enhanced toughness for use as cryotank structure. The approach taken includes E-beam curing combined with automated tape placement, and using non-autoclave, heated head automated tape placement, to fabricate PMC's containing thin interleafed thermoplastic films designed with enhanced resistance to $\mathrm{O}_{2}$ and $\mathrm{H}_{2}$ permeation. A photograph of a 4-ply composite material with a 0.003-in. poly ether ether ketone (PEEK) film interleafed between plys is shown in Fig. 7. In several cases, the PEEK film has increased the ply strength of the material in addition to reducing the diffusion of oxygen through the material ${ }^{6}$.

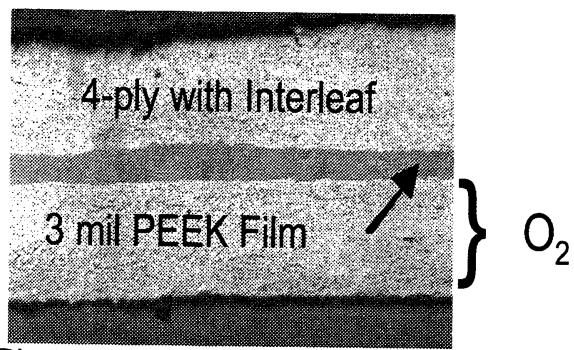

Fig. 7 Photograph of composite material with PEEK film.

One major activity is to develop non-autoclave adhesives to bond composite panels. This involves the development of high flow adhesives (LaRC PETI-8) that can be processed with vacuum bag/oven only techniques without requiring external autoclave pressure and the study of hot melt thermoplastic adhesives that provide high mechanical strength on cooling. The goal is to demonstrate advanced adhesives for non-autoclave composite processing with tensile shear strength of 3000 psi at $350^{\circ} \mathrm{F}$. Accomplishing this goal would provide significant manufacturing cost reduction and increase the cryotank design space, since the restriction of autoclaves would not be required. Phenylethynyl terminated imides (PETI) have been prepared that show excellent adhesive strengths when bonding titanium adherends under vacuum bag/oven processes. Currently, work is progressing on evaluating these adhesives with composite adherends under the same processing conditions. Future work will focus on the surface treatment of composites and attempting to bond the composites without distortions of the composite material.

The MMC Constituents and Processes task is focused on airframe primary and hot structure, specifically advanced $\mathrm{Ti}$ and intermetallic MMC's for $1200^{\circ} \mathrm{F}-1500^{\circ} \mathrm{F}$ use, novel lightweight metallic systems for $1500^{\circ} \mathrm{F}-2000^{\circ} \mathrm{F}$, efficient joining processes, and lightweight protective coatings. The goal of the task is to develop lightweight high-temperature MMC's for robust low-cost metallic hot airframe structure, as illustrated in Fig. $8^{7}$. The approach taken to achieve this goal is to develop high-temperature $\mathrm{Ti}$ and $\mathrm{Ti}_{x} \mathrm{Al}$ alloys and MMC's for $1200^{\circ} \mathrm{F}-1500^{\circ} \mathrm{F}$, develop novel lightweight metallic systems for $1500^{\circ} \mathrm{F}-2000^{\circ} \mathrm{F}$, develop efficient joining processes for incorporation of MMC hot structure, and develop lightweight coatings for environmental protection and thermal control ${ }^{8}$. This task will also develop forming processes for fabricating complex MMC shapes and joining processes for incorporating MMC's into appropriate structural concepts. In addition to the material development work of this task, modeling is included. The modeling includes the refinement of existing $\mathrm{Ti}$ MMC laminate micromechanical models, the development of interface models with structural design models, and the modeling of the thermal behavior required to optimize innovative MMC structures.

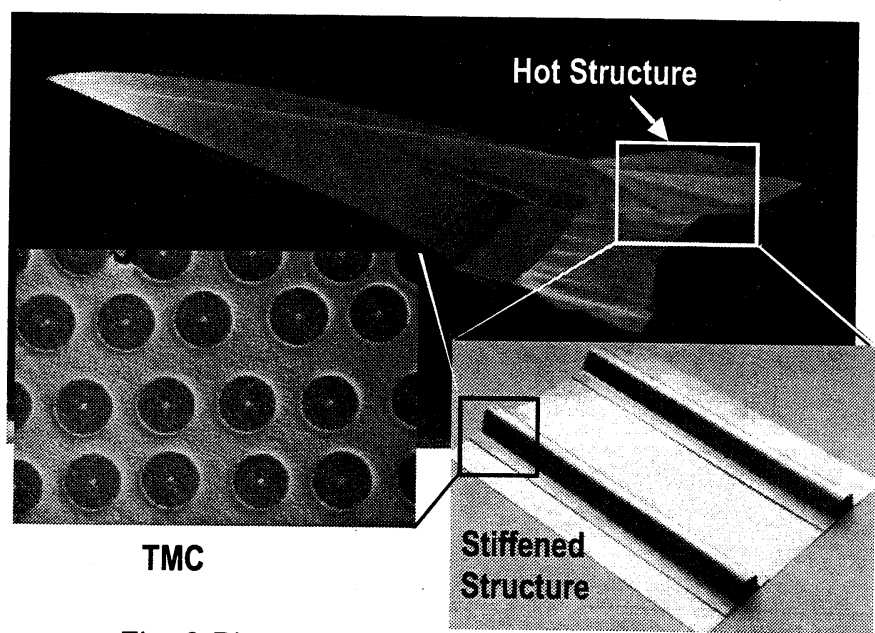

Fig. 8 Photograph of a stiffened TMC panel.

The objective of the $\mathrm{CMC}$ Constituents and Processes task is the development of composites with improved mechanical reliability and cyclic durability, which enable application in airframe control surfaces for reusable hypersonic vehicles. Current $\mathrm{C} / \mathrm{SiC}$ composites pair a low to negative CTE carbon fiber with a chemical vapor infiltrated SiC matrix having a CTE on the order of 3.5 $\mathrm{ppm} /{ }^{\circ} \mathrm{C}$, resulting in a composite which has matrix microcracking on fabrication, and hence, poor durability when stressed under oxidizing conditions (See Fig. 9). Most of the current composite systems show poor matrix homogeneity (some tows are tightly packed while others are largely spaced) resulting in large matrix voids. Use of larger tow sizes, required in complex components, 
introduces the issue of poor infiltration of matrix into the tows, resulting in poor mechanical performance. Optimizing fiber loading of 2D fabric and $3 D$ architectures is necessary to eliminate matrix microcracking and attain more uniform microstructures, improved infiltration, and mechanical properties and durability under cyclic thermomechanical loading.

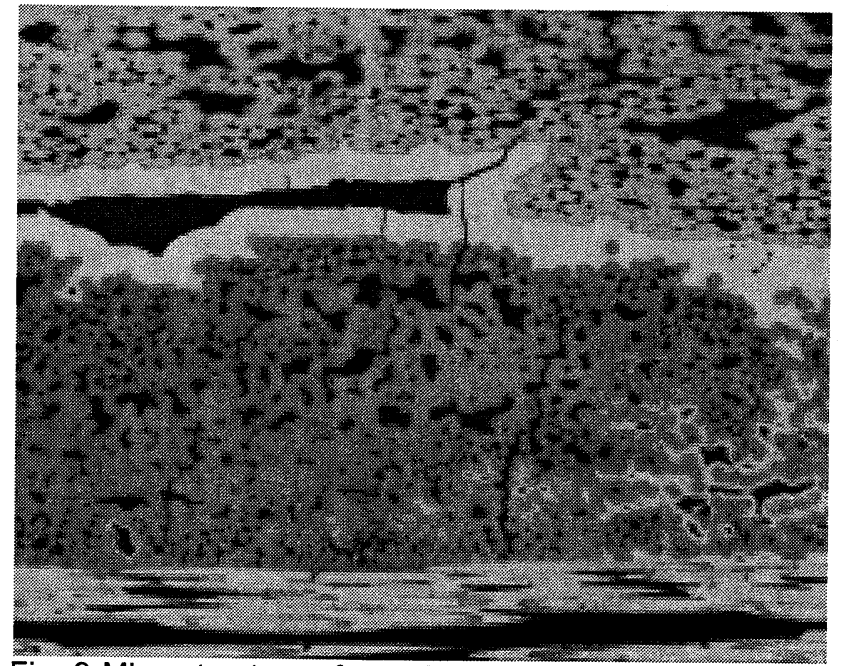

Fig. 9 Microstructure of a typical C/SiC composite with T$3003 \mathrm{k}$ fiber showing large voids between tows, poor tow infiltration, and matrix microcracking.

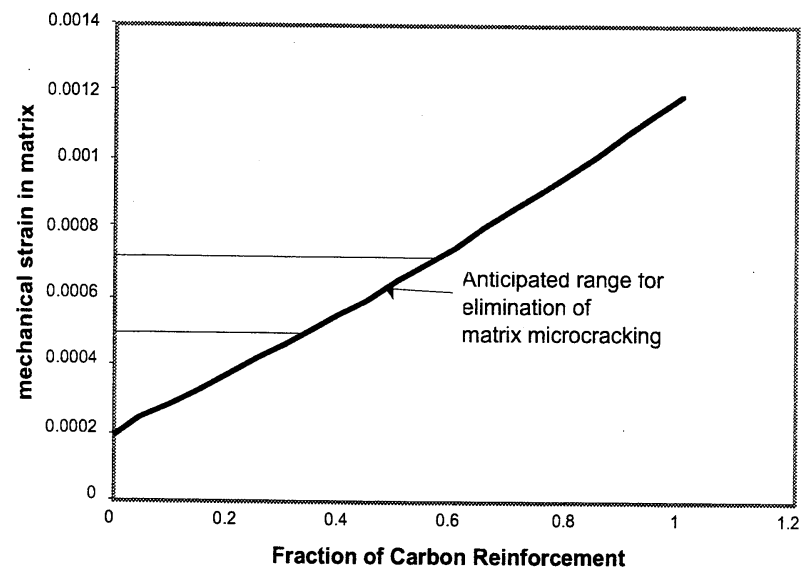

Fig. 10 Effect of co-mingling $\mathrm{C}$ and SiC fibers on composite residual stress.

The approach to improve material uniformity and properties is an optimization of fiber volume fraction and tow spacing, based on extensive experience in $\mathrm{SiC} / \mathrm{SiC}$ composites, combined with the introduction of SiC ceramic fibers co-mingled with the carbon fibers to reduce the composite residual stress and eliminate matrix cracking during fabrication. A preliminary one-dimensional analysis of residual stress as a function of fraction of carbon fiber co-mingled with SiC fibers, shown in Fig. 10, is being used to select the $\mathrm{C} / \mathrm{SiC}$ ratios for initial composite fabrication and testing. Ultimate proof of concept will be demonstrated under thermomechanical fatigue conditions, with a goal of improved cyclic life. Also, lower CTE matrices will be evaluated.

Additionally the task takes advantage of synergies with propulsion materials tasks focused on increased durability, which include consideration of matrix inhibition and alternative interphases. Interaction parameters using a combination of these approaches will be evaluated.

The Integrated Airframe Structure Development task is focused on both hot and warm (insulated) structures and integrated fuselage/tank/TPS systems. The objective is the development and validation of structural systems that show the best potential of meeting program goals for the vision vehicle. The approach taken to achieve this goal is to develop candidate hypersonic airframe concepts including structural arrangement,. load paths, thermalstructural wall design, thermal accommodation features, and integration of major components; optimize thermalstructural configurations; and validate concepts through a building-block test program and generate data to improve and validate analytical and design tools.

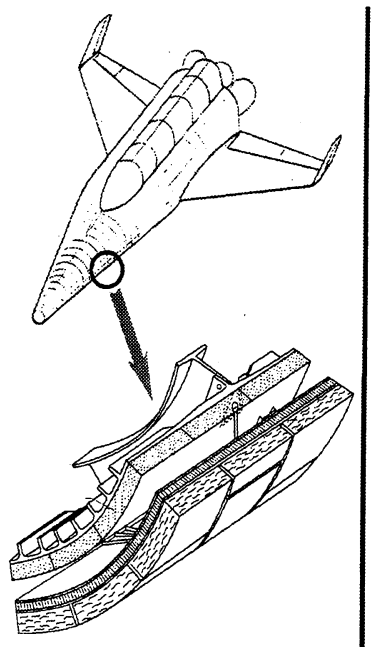

Integral tank configuration with standoff aeroshell wall

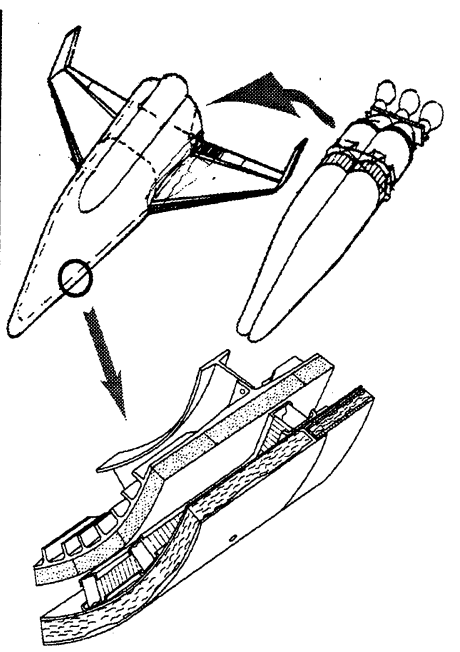

Non-integral tank configuration with standoff structural aeroshell wall
Fig. 11 Schematic of integral and non-integral tanks.

The structural arrangements considered include both integral, where the tank carries internal and external, aerothermodynamic loads, and non-integral, where the tank carries only internal pressure loads and the tank can expand and contract. An integrated wall construction is an approach, or design philosophy, where the entire structure (the tank, insulation, TPS, etc.) is designed together to account for thermal and mechanical loads. This task considers all options for an integrated structure, including TPS, cold structure, hot structure, tanks, insulation, and all types of material systems. An illustration of integral and non-integral tanks is shown in Fig. 11.

\section{Thermal Protection Systems}

The Thermal Protection Systems sub-project objectives are the development and demonstration of acreage TPS 
with decreased thermal conductivity, development of leading edge materials and concepts for reuse at extremely high heat fluxes, and development of dynamic seals for control surfaces. To accomplish the objectives, three tasks are identified. The Ceramic Leading Edges and Acreage TPS task is developing durable low thermal conductivity acreage materials, ultra-high temperature ceramics (UHTC) material optimization, and functionally graded UHTC's. The next task, Refractory Composite Leading Edges, is developing heat pipe cooled leading edge technologies and evaluating coatings for sharp ${ }^{\circ} \mathrm{F}$. The final TPS task is Advanced Control Surface Seals and is focused on developing high-temperature seal concepts and verifying performance in simulated environments.

The Ceramic Leading Edges and Acreage TPS task is focusing on the development of sharp leading edges and acreage TPS with the goal of improving performance margin with highly reliable sharp ceramic leading edge systems and lower thermal conductivity acreage insulation. This task involves work in three areas: First, thin, durable low thermal conductivity acreage materials will be studied. Hypersonic airbreathers will incorporate thin aerodynamic elements to help reduce drag. The thermal conductivity of existing materials produces excessively thick TPS solutions because of the large integrated heat loads. Advanced materials development with reduced conductivity will enable production of thin aerostructures with attendant reduced system weight. Second, methods to optimize UHTC material will be studied. The third task involves functionally graded UHTC's. Here, material transition technologies will enhance the durability and ease the integration of UHTC TPS. Application of CARES/Ceramic Life Design Technology to UHTC's will contribute to the optimization of performance margin for these materials.

The Refractory Composite Leading Edges task is focused on sharp passive leading edges with use temperature $>3600^{\circ} \mathrm{F}$ and heat-pipe-cooled leading edges (HPCLE). As illustrated in Fig. 12, the goal in developing high-temperature leading edges is for the leading edge to remain passive up to as high a temperature as possible before transitioning to a heat-pipe design, and, for higher heat fluxes, an actively cooled design. The transition to heat pipes and then active cooling for higher heating levels increases the cost, complexity, and weight of the leading edge. This task addresses the passive and heat-pipe options.

The goal of the passive portion of the task is to develop high-temperature composite material systems for reusable applications with $\mathrm{T}>3600^{\circ} \mathrm{F}$. Challenges to developing a passive leading edge with these high use temperatures are providing coatings with reusable high temperature oxidation protection and developing a fiber architecture that will result in a composite with stresses below allowables.

A $\mathrm{C} / \mathrm{C}$ heat-pipe-cooled leading edge (HPCLE) is illustrated in Fig. $13^{9}$. The leading edge consists of refractory metal heat pipes embedded in a refractory composite structure. The heat pipes are oriented normal with the leading edge and have a "D-shaped" cross section, with the flat portion of the " $D$ " forming the wing- leading-edge outer surface. The $\mathrm{C} / \mathrm{C}$ structure sustains most of the mechanical structural loads and also offers ablative protection in the event of a heat-pipe failure. The maximum operating temperature capability of coated $\mathrm{C} / \mathrm{C}$ composite materials for the primary structure of the leading edge is high $\left(-3000^{\circ} \mathrm{F}\right)$ relative to refractory metals, which are typically limited to temperatures of approximately $2400^{\circ} \mathrm{F}$. The potentially higher operating temperature of the concept increases the radiation heat-rejection efficiency of the heat-pipe-cooled leading edge and permits reductions in the mass of the leading edge for a given leading-edge radius. In addition, the higher operating temperature increases the total heat load that can be accommodated passively by the heat pipe (i.e., no forced convective cooling required). For many trajectories, the high operating temperatures of the present design help eliminate the need for active cooling during both ascent and descent, thus eliminating the need for carrying additional hydrogen fuel (coolant) into orbit. Since many hypersonic vehicle concepts return unpowered for landing, the additional hydrogen fuel needed for cooling during descent would result in a mass penalty.

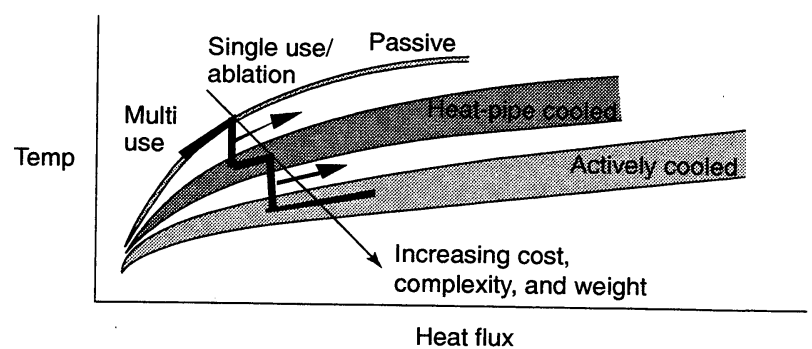

Fig. 12 Illustration of goal to increase temperature capability before moving to more complex designs.

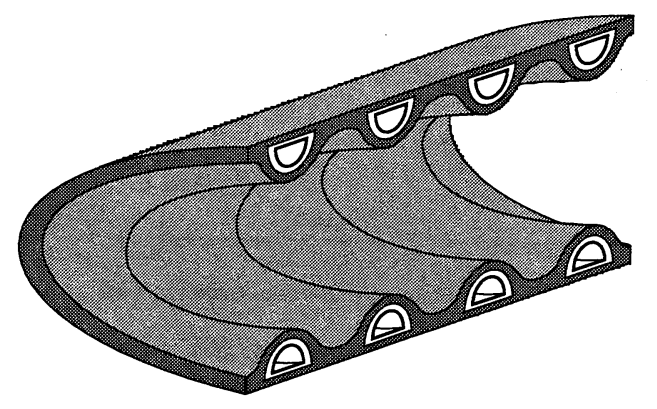

Fig. 13 Schematic drawing of a heat-pipe-cooled wing leading edge.

The successful development of a HPCLE requires the utilization of a carbon diffusion barrier on the refractory metal heat pipe and a compliant layer between the heat pipe and the composite material in which it is embedded. A study is underway to evaluate multiple combinations of noble metal coatings as a carbon diffusion barrier. In addition, a finite element analysis will evaluate the thermal stress issues associated with difference in coefficient of thermal expansion between refractory metal heat pipes and 
the refractory composite in which it is embedded. The resulting model will be used to develop the compliant layer to alleviate excess thermal stresses. Both $C / C$ and other CMC material systems will be evaluated for potential use in the heat-pipe design.

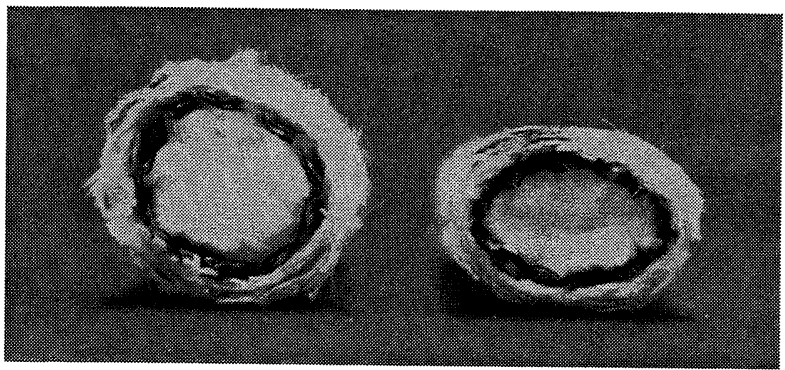

Fig. 14 Current state-of-the-art control surface seals before (left) and after (right) $1900^{\circ} \mathrm{F}$ temperature exposure.

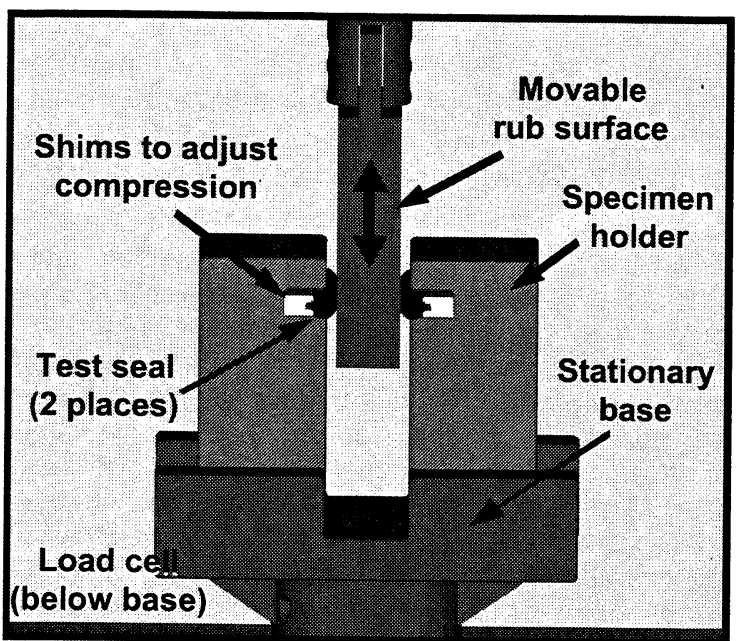

Fig. 15 Schematic of hot scrub test rig being fabricated to test seals.

The Advanced Control Surface Seals task is focused on the development of high-temperature, reusable, resilient seal concepts and the verification of their performance in simulated environments. Testing has revealed that current state-of-the-art control surface seals take on a permanent set and lose resiliency after exposure to $1900^{\circ} \mathrm{F}$ while in a compressed state as shown in Fig. 14. Such a permanent set can cause gaps to form around the seals that allow hot gases to flow past the seals. In this task, new resilient, high-temperature $\left(2000^{\circ} \mathrm{F}\right)$ control surface seal concepts will be evaluated under representative conditions (temperatures, pressures, scrubbing, etc.). To achieve this, new test rigs are under development that include a hot compression test rig, hot scrub test rig, and a combined room temperature flow and scrub test rig. Both hot compression and hot scrub tests will be performed in the same test rig using different test fixturing. A schematic of the hot scrub test fixturing is shown in Fig. 15. Computationally, aero-thermal-structural analyses of seals have been performed using tightly integrated CFD-
FEA analysis tools. Also, seal environmental exposure tests will be performed in arc jet (e.g., Fig. 16) and thermal acoustic facilities to evaluate control surface seals.

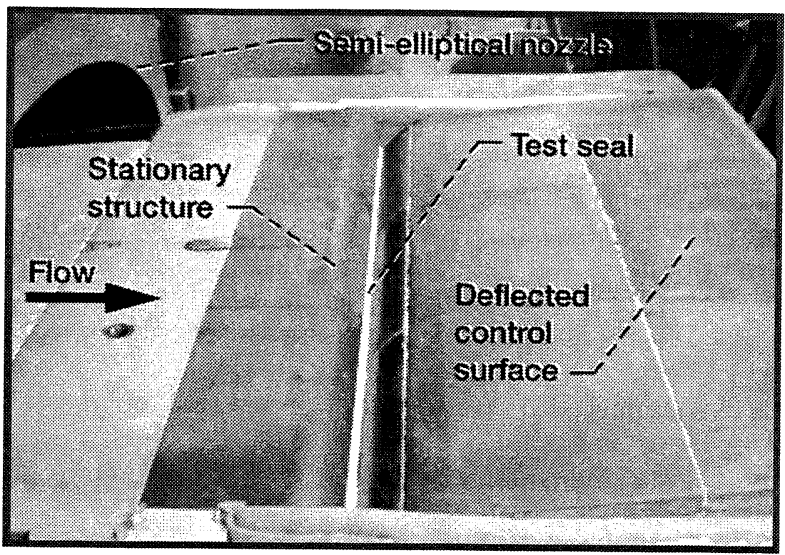

Fig. 16 Photograph of control surface seal and control surface in arc-jet facility at NASA Ames.

\section{Aerothermodynamics}

Aerothermodynamics determines the flyability and survivability of aerospace vehicles. For the successful design and flight of an aerospace vehicle, it must pass through the aerothermodynamics "gate." This discipline defines the environment about a vehicle, both within the flow field and most importantly at the surface. It is therefore a blend of fluid mechanics, gas dynamics, aerodynamics and aeroheating, and includes hightemperature, chemically reacting flows, radiation and ionization with associated extreme surface temperatures and blackout during reentry. The Aerothermodynamics sub-project must address issues for a wide spectrum of possible hypersonic airbreather configurations, ranging from relatively small flight demonstrators to the access to space vision vehicle, which will dock with the International Space Station (ISS). Two tasks address these issues, each having a fairly broad scope: First, the Rapid Aerothermodynamic Environment Definition task is focused on reducing the time and increasing the fidelity for aerothermodynamic design, development, and assessment of airbreather vehicles, through development of revolutionary experimental and computational tools. The objective of the second task, Essential Aerothermodynamic Technologies, is to enhance the performance margin of both flight demonstrators and an ultimate vision vehicle through development of enabling technologies such as transition prediction and control and vehicle flyability/survivability. The successful completion of the tasks in this sub-project will reduce vehicle aerodynamic and aeroheating uncertainties, thus reducing dry weight and enabling gains in performance margin, which in turn provide improved landing site flexibility and better crew survivability/safety.

The goal of the Rapid Aerothermodynamic Environment Definition task is to advance aerothermodynamic experimental testing and computational methods in order to reduce time and cost and increase the fidelity/scope of 
aerothermodynamic information by two orders of magnitude over the next fifteen years. On the experimental side, this task addresses issues including: model fabrication, which is the experimental "long-pole" from a time perspective; global surface measurements (such as high-temperature pressure-sensitive paints) ${ }^{10}$ and nonintrusive flow field measurements. ${ }^{11}$ Low-shrinkage metal casting, rapid prototyping for aerodynamic models and casting patterns, direct fabrication methods such as electron-beam metal fabrication and co-sinterable ceramic/metal deposition for ceramic aeroheating models complete with leads for instrumentation are all being investigated. The ultimate goal is rapid, automated, lights-out machining and integrated process control methods at each step of the model fabrication, which provides quality. Pressure sensitive paints (PSP's) are being applied to models tested in the high-temperature environments of hypersonic wind tunnels with the final objective to obtain simultaneous, global, quantitative surface pressure and temperature measurements (as spatial and bit resolutions of off-theshelf cameras improve). Automated texture mapping is being developed to rapidly map PSP, thermographic phosphor, and IR data onto vehicle design environment meshes so that the experimental aerothermodynamic data can be rapidly synthesized into design processes providing inputs to structural and TPS modules. Finally, global flow field measurement techniques such as planar laser-induced fluorescence (PLIF) are being driven to quantitative levels to provide validation of computational fluid dynamics (CFD) and understanding of difficult fluid phenomena as required for numerical modeling (See Fig. 17).

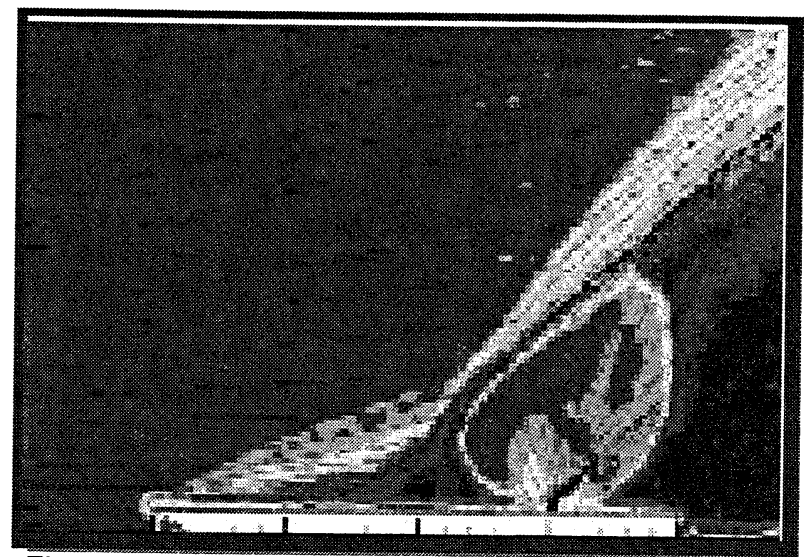

Fig. 17 Planar laser induce fluorescence image of jet expanding into rarefied $M=14$ flow, University of Virginia.

Parallel accomplishments are being achieved for CFD, where one of the "long poles" is the creation of surface and volume grids. Procedures and methodologies are being developed to rapidly take CAD geometry information and generate unstructured grids as shown in Fig. 18. Work is also being done to create unstructured overset chimera grids to address hypersonic stage separation issues for both flight demonstrators and the ultimate vision vehicle. Physical models from benchmark internal and external viscous high temperature chemically reacting flow solvers are being synthesized with an unstructured $3 D$ viscous flow solver to produce a flexible, high-fidelity tool to rapidly predict environments tip-to-tail on future hypersonic vehicle concepts.

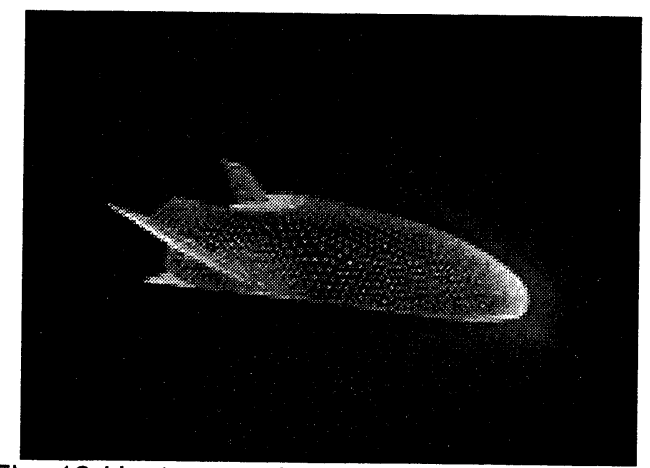

Fig. 18 Unstructured volume mesh about X-33.

Use of hypersonic airbreather vehicles for access to space represents a significant leap in vehicle technology development. The objective of the Essential Aerothermodynamic Technologies task is to enhance the performance margin of both flight demonstrators and an ultimate vision vehicle through development of enabling technologies pertaining to vehicle fly-ability/survivability.

First, an understanding of boundary layer flow transition is critical for a number of reasons. Skin-friction drag due to turbulent flow on slender body surfaces is greater than for laminar flow and thereby requires more thrust to overcome this drag. Turbulent flows at the surface can increase heating by a factor of 3 to 5 times over that for laminar flow. Also, scramjet engine performance is enhanced by the ingestion of a turbulent flow in the inlet through improved fuel mixing and reduction of internal flow separation within the engine. In this task, methods of controlling boundary layer/shear layer transition are being investigated including static trips, synthetic jets, and mass injection. Shown in Fig. 19 is a thermograghic phospher heating image of the effect of trips on an X-43A model forebody experimentally obtained at Mach 6 . Note that the image provides a view of the transition front location between the laminar (blue) and turbulent (red) boundary layer regions as the flow proceeds from left to right. Correlations from hypersonic quiet tunnel research will link conventional facility transition work to flight conditions. Finally, transition modeling from $1^{\text {st }}$ principles using the direct simulation Monte Carlo (DSMC) method is being researched with flow breakdown in 3D model problems.

While the design of reaction control system (RCS) jets is well matured, the accurate determination of their effectiveness in various flight environments is not. Research is currently being focused on understanding RCS interactions, both computationally and experimentally throughout the hypersonic/hypervelocity speed regime. In addition, the interaction of a number of jets on each other is being considered in order to "morph" a vehicle surface by mass addition, which may ultimately lead to the elimination of vehicle control surfaces in the long term. 
Some studies have shown the promise of significant positive effects on aerodynamic performance by the introduction of plasmas in hypersonic shock layers. ${ }^{12}$ Research is currently being performed experimentally with an emphasis on improved generation of plasmas in hypersonic facilities (See, for example, Fig. 20). From there, the use of plasmas will be investigated in various hypersonic wind tunnels from the standpoint of reducing drag and possibly mitigating sonic boom to enable supersonic flight over land.

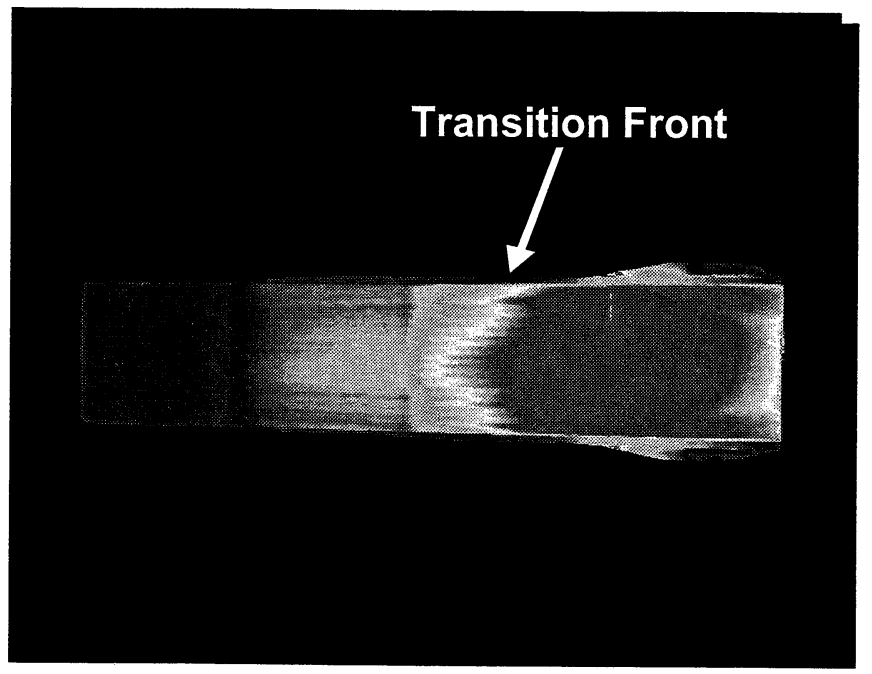

Fig. 19 Transition on X-43A model obtained in LaRC Aerothermodynamics Lab using two-color phosphor thermography.

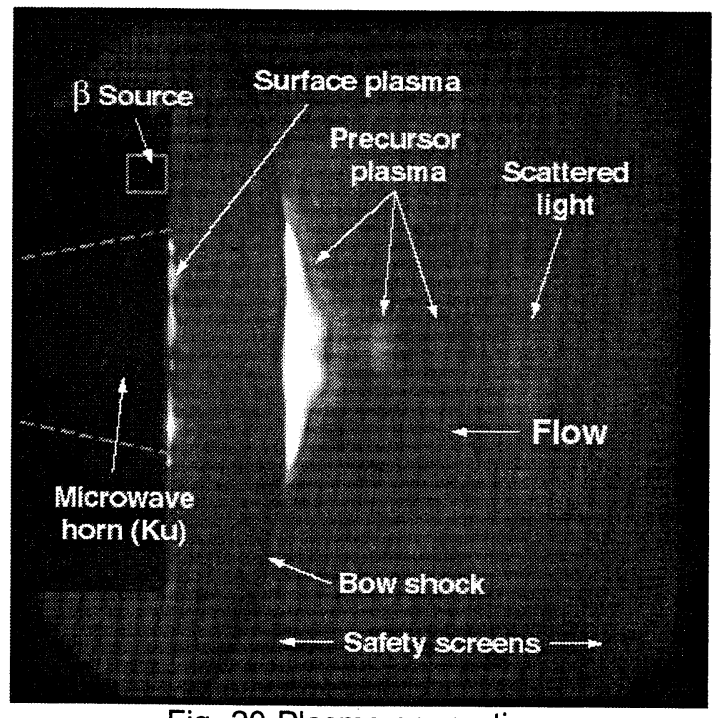

Fig. 20 Plasma generation.

\section{Airframe/Propulsion Flowpath Technology}

For completeness, the Airframe/Propulsion Flowpath Technology sub-project is described here. The objectives of the sub-project include technology development to support ASTP ground and flight demonstration goals and space-access vision vehicle development. This will include test technique development and performance database generation for engine flowpath and vehicle development. The Aerothermodynamics and Vehicle Development task will define aero-heating mechanisms for scramjet inlet configurations, develop alternative mechanisms for boundary layer trip control for improved inlet performance, identify methodologies for aero-propulsive data base development, and evaluate airframe integration effects of candidate flight configurations and advanced control mechanisms. The Mid-Speed Combustor Development task will develop a comprehensive performance database for hydrogen and hydrocarbon combustors. provide risk mitigation testing for $\mathrm{X}-43 \mathrm{C}$ and $\mathrm{X}-43 \mathrm{~B}$ RBCC and TBCC combustor configurations, and examine scalability of hydrocarbon combustor data to hydrogen vision vehicle development. The Variable-Geometry Engine Performance and Operability task will focus on the development of hydrogen and hydrocarbon-fueled variable geometry engine performance, a hypervelocity scramjet engine, and dualMode scramjet controls. The final task, TPS Arc-Jet Testing, will provide arc-jet testing of materials, seals, and attachments in flight-like high enthalpy environments and validate key analysis and design tools.

\section{Concluding Remarks}

The Airframe R\&T Project has significantly reworked tasks to focus on technical challenges confronting hypersonic airbreathing vehicles. These tasks address many of the technical challenges of the vision vehicle (2025 time frame), and include a mix of low and medium TRLs. Technical areas being worked include aerodynamics, aerothermodynamics, airframe/propulsion flowpath technology, materials development, structural concepts, TPS, seals, leading edges, IVHM, and analysis/design tools.

\section{ACKNOWLEDGEMENTS}

Researchers at multiple NASA centers are performing the work in this project. Their teaming and hard work is greatly appreciated and is key to the success of both the Airframe project and the Advanced Space Transportation Program.

\section{REFERENCES}

1. Wood, K., Brown, T., Rogowski, R., Jensen B.: "Fiber Optic Sensors for Health Monitoring of Morphing Airframes: I. Bragg Grating Strain and Temperature Sensor". Smart Materials \& Structures, pp. 163-169, 2000.

2. Childers, B.A., Froggatt, M.E., Allison, S.G., Moore, T.C., Hare, D.A., Batten, C.F., Jegley, D.C.: "Use of 3000 Bragg Grating Strain Sensors Distributed on Four Eight-Meter Optical Fibers During Static Load Testing of a Composite Structure". SPIE's 8th Annual International Symposium on Smart Structures \& Materials, March, 2000. 
3. Melvin, L., Childers, B., Rogowski, R., Prosser, W., Moore, J., Froggatt, M.E., Allison, S., Wu, M.C., Bly, J., Aude, C., Bouvier, C., Zisk, E., Enright, E., Cassadaban, Z., Reightler, R., Sirkis, J., Tang, I., Peng, T., Wegreich, R., Garbos, R., Mouyos, W., Aidel D., Boden P.: "Integrated Vehicle Health Monitoring (IVHM) for Aerospace Vehicles, Structural Health Monitoring - Current Status and Perspectives". (Edited by: Chang, F.K.) Proceedings of the International Workshop on Structural Health Monitoring, Stanford University, Stanford CA, Technomic Publishing Co. Inc., September 18-20, 1997.

4. Froggatt, M.E.: "Distributed Measurement of the Complex Modulation of a Photoinduced Bragg Grating in an Optical Fiber". Appl. Opt. 35, pp. 5162-5164, 1996.

5. Richards, L., Piazza, A., Parker, A., Hudson, L., Carman, G., Mitrovic, M., Lee, D., Stewart, A.: "Fiber Optic Sensor Development for Structural Health Monitoring of Reusable Launch Vehicles". Proceedings of the 3rd International Workshop on Structural Health Monitoring, Stanford University, Palo Alto, CA, pp. 133-143, September 12-14, 2001.

6. Grimsley, B.W., Cano, R.J., Johnston, N.J., McMahon, W.M.: "Hybrid Composites for LH2 Fuel Tank Structure". 33rd International SAMPE Conference, Seattle, WA, Vol. 33, pp. 1224-1235, November 4-8, 2001.

7. Smith, P.R., Rosenberger, A.H., Rhodes, C.G.: "Orthorhombic Titanium Aluminide Metal Matrix Composites (O TMCs) - A Review". Report \#AFRL-MLWP-TR-2000-4083, October, 1999.

8. Bird, R.K., Wallace, T.A.; Sankaran, S.N.: "Development of Protective Coatings for High-Temperature Metallic Materials". Proceedings from Elevated Temperature Coatings - Science and Technology IV, (Edited by: Dahotre, N.D., Hampikian, J.M., Morral, J.E.) The Minerals, Metals, and Materials Society, pp. 181-196, Warrendale, PA, 2001.

9. Glass, D.E., Camarda, C.J., Merrigan, M.A., Sena, J.T.: "Fabrication and Testing of Mo-Re Heat Pipes Embedded in Carbon/Carbon," Journal of Spacecraft and Rockets, Vol. 36, \#1, pp. 79-86, 1999

10. Buck, G.M.: "Rapid Model Fabrication and Testing for Aerospace Vehicles," AIAA Paper 2000-0826, January, 2000.

11. Staack, D., McDaniel, J.C., Glass, C.E., Miller, C., "Experimental Study of Interacting Rarefied and Continuum Flows". AlAA Paper \#2001-2762, presented at the $35^{\text {th }}$ AIAA Thermophysics Conf., Anaheim, CA, June 11-14, 2001.

12. Exton, R.J., et al.: "On-Board Projection of a Microwave Plasma Upstream of a Mach 6 Bow Shock," Physics of Plasmas, Vol. 8, \#11, pp. 5013-5017, November, 2001. 
Public reporting burden for this collection of information is estimated to average 1 hour per response, including the time for reviewing instructions, searching existing data sources, gathering and maintaining the data needed, and completing and reviewing the collection of information. Send comments regarding this burden estimate or any other Reports, 1215 Jefferson Davis Highway Suite 10. Washington, DC 20503.

\begin{tabular}{|l|l|l|}
\hline 1. AGENCY USE ONLY (Leave blank) & $\begin{array}{l}\text { 2. REPORT DATE } \\
\text { July } 2002\end{array}$ & $\begin{array}{c}\text { 3. REPORT TYPE AND DATES COVERED } \\
\text { Technical Memorandum }\end{array}$ \\
\hline
\end{tabular}

\title{
4. TITLE AND SUBTITLE
}

Airframe Research and Technology for Hypersonic Airbreathing Vehicles

\section{FUNDING NUMBERS}

713-10-90-01

\section{AUTHOR(S)}

David E. Glass, N. Ronald Merski, and Christopher E. Glass

NASA Langley Research Center, Hampton, VA 23681

\author{
7. PERFORMING ORGANIZATION NAME(S) AND ADDRESS(ES) \\ NASA Langley Research Center \\ Hampton, Va 23681-2199
}

8. PERFORMING ORGANIZATION REPORT NUMBER

\section{SPONSORING/MONITORING AGENCY NAME(S) AND ADDRESS(ES)}

National Aeronautics and Space Administration

Langley Research Center

Hampton, VA 23681-2199

10. SPONSORING/MONITORING AGENCY REPORT NUMBER

NASA/TM-2002-211752

\section{SUPPLEMENTARY NOTES}

\begin{tabular}{l|l|}
\hline 12a. DISTRIBUTION/AVAILABILITY STATEMENT & 12b. DISTRIBUTION CODE \\
Unclassified-Unlimited & \\
$\begin{array}{l}\text { Subject Category } 15 \\
\text { Availability: NASA CASI (301) } 621-0390\end{array}$ & \\
\hline
\end{tabular}

\section{ABSTRACT (Maximum 200 words)}

The Hypersonics Investment Area (HIA) within NASA's Advanced Space Transportation Program (ASTP) has the responsibility to develop hypersonic airbreathing vehicles for access to space. The Airframe Research and Technology (AR\&T) Project, as one of six projects in the HIA, will push the state-of-the-art in airframe and vehicle systems for low-cost, reliable, and safe space transportation. The individual technologies within the project are focused on advanced, breakthrough technologies in airframe and vehicle systems and cross-cutting activities that are the basis for improvements in these disciplines. Both low and medium technology readiness level (TRL) activities are being pursued. The key technical areas that will be addressed by the project include analysis and design tools, integrated vehicle health management (IVHM), composite (polymer, metal, and ceramic matrix) materials development, thermal/structural wall concepts, thermal protection systems, seals, leading edges, aerothermodynamics, and airframe/propulsion flowpath technology. Each of the technical areas or sub-projects within the Airframe R\&T Project is described in this paper.

\begin{tabular}{|l|l|l|l|}
\hline $\begin{array}{l}\text { 14. SUBJECT TERMS } \\
\text { hypersonic vehicles, structures and materials, aerothermodynamics }\end{array}$ & $\begin{array}{c}\text { 15. NUMBER OF PAGES } \\
15\end{array}$ \\
\cline { 3 - 4 } & 16. PRICE CODE \\
\hline $\begin{array}{l}\text { 17. SECURITY CLASSIFICATION } \\
\text { OF REPORT } \\
\text { Unclassified }\end{array}$ & $\begin{array}{c}\text { 18. SECURITY CLASSIFICATION } \\
\text { OF THIS PAGE } \\
\text { Unclassified }\end{array}$ & $\begin{array}{c}\text { 19. SECURITY CLASSIFICATION } \\
\text { OF ABSTRACT } \\
\text { Unclassified }\end{array}$ & $\begin{array}{c}\text { 20. LIMITATION } \\
\text { OF ABSTRACT }\end{array}$ \\
\end{tabular}

